\title{
Cuento: Sugestión
}

\section{Tale: Suggestion}

\author{
Jhonattan Andrés Benavides Jurado \\ Estudiante Literatura \\ Universidad Autónoma de Bucaramanga \\ jbenavides158@unab.edu.co
}

Recibido el 18 de abril del 2015

Aprobado el 04 de mayo del 2015

Las hojas cargadas de frases insospechadas se deslizaron sobre la mesa, reafirmando la sentencia del editor: no vale la pena escribir más sobre este asunto.

Héctor volvió a casa con la sensación del deber incumplido. El rumbo de su investigación se había tornado difuso y sus primeras conclusiones eran tan alarmantes como improbables. No resultó difícil adivinar el rechazo que provocaría su historia en el diario para el que trabajaba, pues surgía justo en el tiempo en el que las únicas páginas que merecían tal atención eran aquellas que se referían al caso de la compañía Air Cup propietaria del misterioso avión comercial que se desintegró en el aire, mientras volaba de Barcelona a Düsseldorf-.

Las últimas líneas habían nacido de su más reciente encuentro con Ángela, quien ahora permanecía en la penitenciaría, aguardando la sentencia definitiva sobre su caso, registrado de forma irreflexiva en los diarios nacionales. Aún estaba vivo en la memoria de Héctor el recuerdo de esa mirada temerosa e iracunda que él relacionaba con la resignación que experimenta quien ha recibido con pesimismo la noticia de un posible aumento en su condena.

Fue un cuatro de marzo. Con sus últimas ínfulas de periodista exitoso llegó a la prisión dispuesto a ultimar detalles de su historia. Antes de someterse a las protocolarias requisas recordó claramente la petición de la cautiva de no usar grabadora de voz e ingresó al patio cinco con un emparedado envuelto en una bolsa de papel, más un libro de notas que esperaba usar en caso de escuchar un dato que exigiera ser registrado con precisión. Por esta razón, a su llegada, no fue extraña la pregunta de Ángela sobre el cumplimiento de dicha 
promesa y, menos aún, la respuesta gestual de Héctor: extendió sus brazos, señaló su propia ropa y le entregó su agenda para que la examinara. Tras esta ilustrativa forma de responder, tomaron asiento — uno frente al otro- y, extrañamente, ella rompió el hielo con una protesta que abogaba por su inocencia.

Era la primera vez en que la presunta asesina negaba la conclusión del caso y declaraba sobre la inocencia de Jorge, su esposo. En este punto Héctor, que ya se disponía a cesar en su empeño ante la imposibilidad de encontrar más información que la consignada por los diarios un día después de la muerte de los niños, se resistía a pensar que toda su indagación tuviera que retornar al blanco silencio de las primeras páginas.

Su resistencia no impidió, sin embargo, que la madre de los pequeños, con algo de frialdad y dolor, reafirmara su posición sobre la injusticia que se estaba cometiendo, a pesar de que el periodista insistió en que no se dejara llevar por las sugerencias de su abogado y en que prestara atención a su propia declaración de culpabilidad tanto como a las pruebas que hablaban en su contra: la sangre en su ropa, las huellas en el arma y las marcas en los cuerpos.

Las lágrimas de Ángela pudieron más que la intención de Héctor de dar por concluida la historia. Así que fue preferible callar y esperar a que ella añadiera un motivo a su alegato.

- Han pasado tres semanas desde nuestra captura y todo es claro ahora...

Su relato continuó por largo tiempo, mientras iba siendo consignado por el periodista en estos términos: Don de Dios era la Iglesia a la que mi esposo y yo habíamos comenzado a asistir cuatro meses atrás, después de que Jorge perdió su empleo en la panadería. El fundador y pastor de esa comunidad cristiana nos acogió desde el primer día con los brazos abiertos. Nuestra desesperación fue cesando a medida que él nos iba animando y nos demostraba la manera en que la providencia nos favorecía. Al fin Dios estaba de nuestra parte. Rápidamente conseguimos empleo en la misma asamblea y nuestra alacena se fue llenando como nunca antes lo había estado.

Asistíamos, cada vez con mayor asiduidad, y obligábamos a nuestros hijos a participar del trabajo con el mismo empeño que nosotros le imprimíamos a las labores que nos eran encomendadas para el crecimiento de la iglesia. El número de fieles que se bautizaban iba en aumento y en la misma medida se nos iba exigiendo mayor compromiso.

No había forma de volver atrás. Luego de un año de participación, empezamos a notar que los pedidos de nuestro Señor eran cada vez más incomprensibles y exigentes, sin embargo, nunca nos atrevimos a cuestionar su voluntad y sí nuestra incompetencia.

La primera solicitud turbadora del pastor, que debimos discutir extendidamente con mi esposo, nos llegó a través de una carta en la que se hablaba implícitamente de la necesidad de purificar mi cuerpo teniendo relaciones sexuales con el enviado de Dios. Mi entrega no había sido suficiente. De modo que cedimos al 
pedido cuando comprobamos que la biblia nos hablaba de la necesidad de ser templos del espíritu de Jehová.

El rito de purificación fue solo el comienzo de los pedidos que desembocaron en la imitación del sacrificio de Abraham. Con el mismo valor del patriarca debíamos entregar a nuestros hijos para que el favor de Dios nos alcanzara. No planeamos muchos detalles, pues no éramos conscientes de estar cometiendo un delito. Más aún, la serenidad fue nuestra compañera para que, sugestionados por el pastor, lleváramos a cabo los designios del Altísimo.

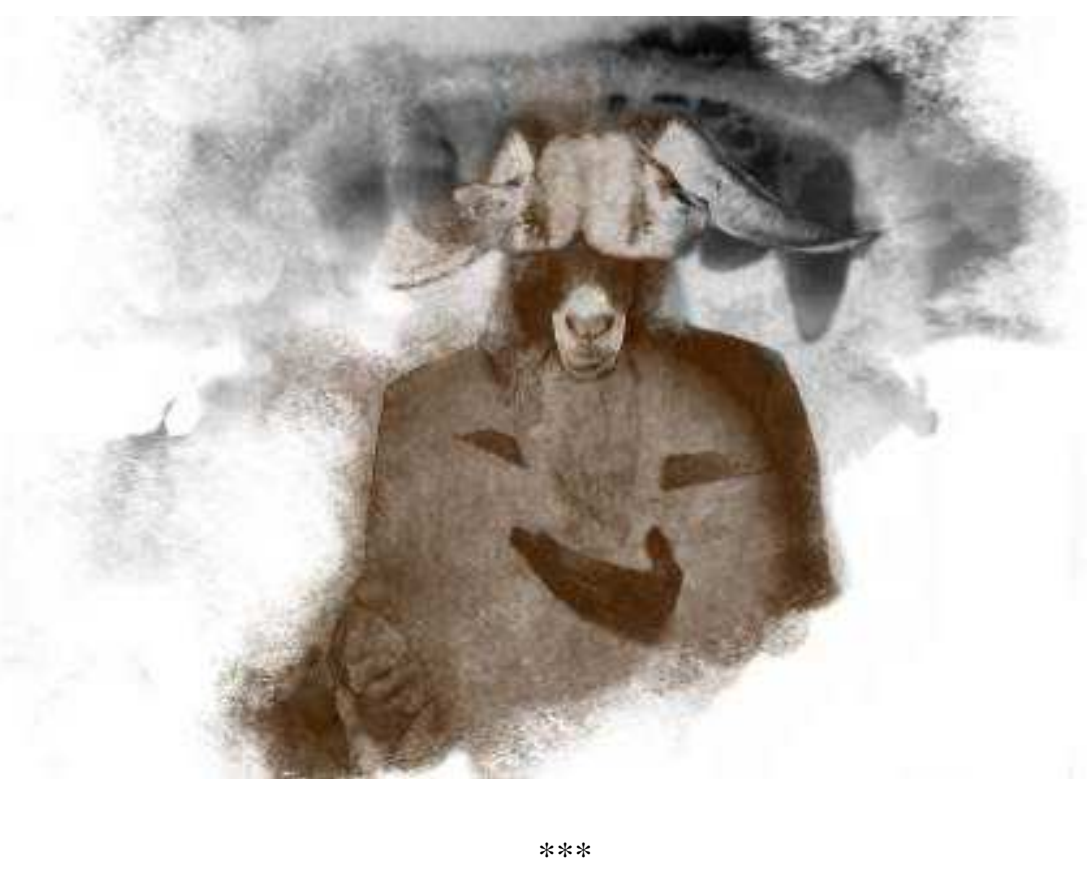

Esa tarde Héctor salió fuertemente trastornado de su entrevista con Ángela. Todo parecía ser cierto por la sinceridad que develaba el rostro de la presidiaria. Hasta entonces ningún signo maternal se había dibujado en sus expresiones faciales, pero en esta ocasión saltaba a la vista el dolor de madre que la estaba agobiando.

El pastor de la iglesia Don de Dios no había aparecido aún entre sus entrevistados, de modo que decidió buscarlo y se encontró ante la sorpresa de que no solo seguía realizando sus labores sin el más mínimo indicio de temor, sino que fue muy fácil acceder a él para cuestionarlo, puesto que su experticia en el manejo del discurso religioso le permitía salir ileso de cualquier cuestionamiento.

A la actitud del pastor se sumaba la falta de pruebas en favor del testimonio de Ángela. Héctor consiguió el permiso necesario para ingresar a la vivienda en la que se había llevado a cabo el asesinato. Las manchas de sangre no habían sido borradas y en el cuarto de los niños estaban intactas sus fotografías, fijadas con cinta en la pared.

Héctor, acompañado de las autoridades asignadas para resolver el caso, removió nuevamente cada cosa en 
busca de pistas que permitieran corroborar las palabras más recientes de la madre de los tres niños asesinados. El tiempo fue su enemigo. Un día entero no fue suficiente para sumar datos a los ya consignados en los informes de criminalística y todo indicaba que no podía renovar su permiso de ingreso a la propiedad.

Al finalizar el día, ya exhausto en su apartamento, recibió una llamada desde un teléfono cuyo número no apareció en el identificador. La voz de la persona que se encontraba al otro lado de la línea sonaba muy parecida a la del pastor. Era evidente que se trataba de él, aunque hubiera olvidado grabar el monólogo a causa del nerviosismo que le produjo el hecho de despertar a esa hora de forma imprevista.

- Jehová es mi pastor nada me falta. Olvide lo que está intentando y acójase al poder de aquel que conoce sus pasos. No intente nada de lo cual pueda arrepentirse en el juicio de Dios.

A pesar de que el nerviosismo continuaba, la sugestión del pastor no parecía haber cobrado efecto. Antes bien, pronto notó que aunque hubiera grabado la llamada, tales palabras no le habrían servido para acusar a nadie. Una vez más corroboraba que el discurso del pastor era tan sutil que fácilmente conseguiría exaltar los ánimos de sus feligreses sin que estos sospecharan las intenciones que fluían más allá de sus palabras.

Este hecho fue suficiente para que Héctor se convenciera de que su última conversación en la cárcel cobraba sentido: el grado de sugestión que silenciaba a Ángela era tan alto que solo la prisión y el tiempo transcurrido en ella le habrían permitido salir de su incapacidad de razonar lo que había ocurrido con sus hijos.

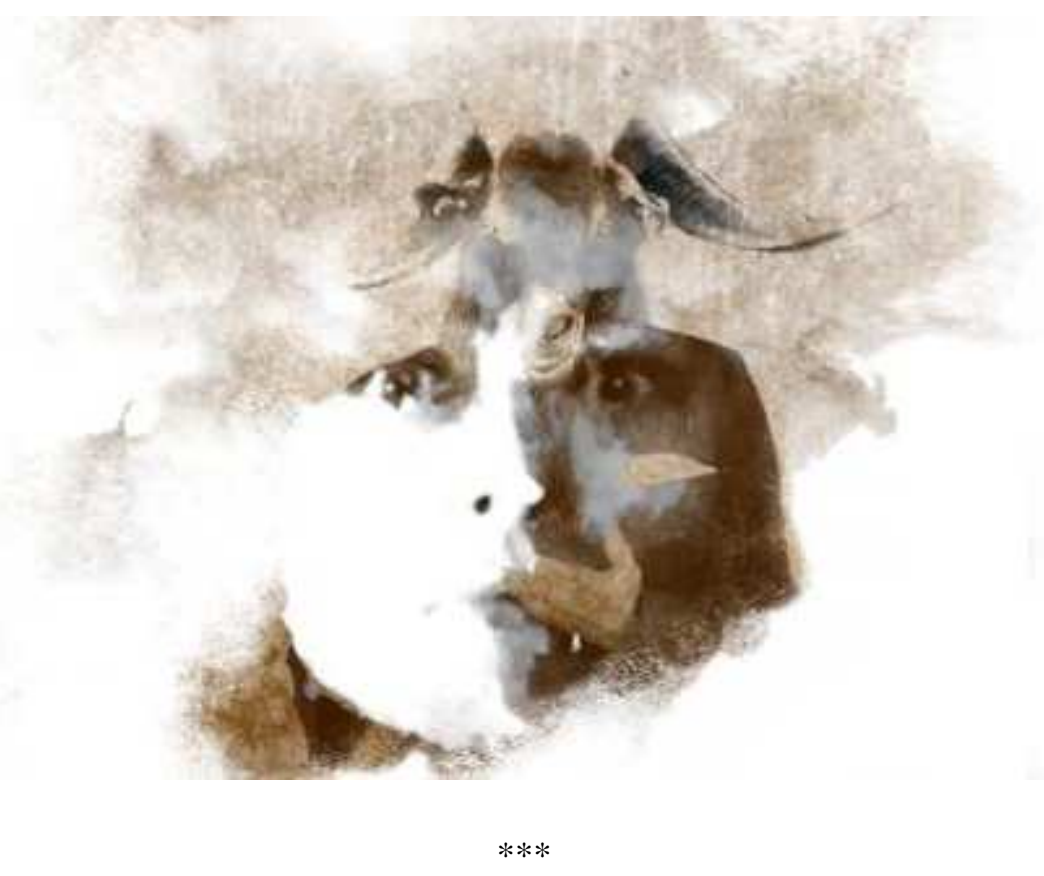

El regreso de Héctor a las oficinas del diario para el cual trabajaba le había producido dos sensaciones. La primera de ellas era de impotencia, pues sabía bien que su historia no podía ser contada con la misma ligereza 
de antes y que, por tanto, el tiempo se había convertido en su peor enemigo. La oportunidad de ser contratado definitivamente se desvanecía con la historia que tenía entre sus manos. El desespero era la segunda sensación que le invadía. Sabía bien que debía hacer algo para impedir la alta condena de Ángela y de su esposo, pero estaba convencido de que nada conseguiría hundir al pastor como era justo.

Finalmente, su nota no sería publicada y su historia se alejaba cada vez más de la posibilidad de ser contada. Tras la negativa del editor, accedió a su blog, como si se tratara de una vuelta atrás y, por tanto, de un regreso al anonimato. Publicó las primeras líneas del resultado de sus más recientes impresiones y conectó sus redes sociales con titulares incompletos: "Los asesinos se confiesan...".

Las líneas publicadas recibieron un considerable número de visitas y pronto su nota fue replicada por algunos diarios locales. A su bandeja de entrada llegaron mensajes que exigían el fin de la historia y algunos contactos de círculos literarios preguntaban si se trataba de una crónica ficticia o del relato de un hecho real. Sabía que no era insignificante el escándalo pero ignoraba que su blog pudiera generar tal impacto en los lectores.

Tras permanecer una tarde entera en su apartamento, preparó todo para regresar a la cárcel la mañana siguiente y salir al encuentro del esposo de Ángela, que le permitiría corroborar aquello que ya conocía y completar una historia que mereciera ser contada.

Tras superar las requisas y arribar definitivamente al patio donde estaban recluidos los acusados y condenados a causa de delitos contra menores de edad, consiguió confrontar a Jorge, quien, con la misma frialdad de Ángela, reafirmó su propia culpa en el caso y se recluyó en el interior de la celda sin pronunciar más palabras.

Con aire de frustración, Héctor salió de allí y se dirigió rápidamente a la cárcel de mujeres, para alcanzar el horario de la última visita. Nuevamente estaba frente a Ángela. Comentó todo lo ocurrido hasta entonces y celebró con voz ansiosa la posibilidad de reducir la pena que les correspondía a los padres por el asesinato de sus tres hijos. Finalizado el relato de Héctor, la voz de la presidiaria sonó fría y tajante: Jehová es mi pastor nada me falta. 